\title{
Chapter 5 \\ Learning Organizations in the Age of Smart Machines
}

\section{Fusion Skills, Augmentation Strategies, and the Role of HRD Professionals}

\author{
Christoph Meier, Sabine Seufert, Josef Guggemos, and Judith Spirgi
}

\subsection{Resurgence of the "Learning Organization"}

We experience the far-reaching changes that are referred to as "digital transformation" on a daily basis: when placing an order via an online store with our tablet; when asking a smart speaker for the weather forecast for the afternoon; when streaming our favorite music from our personal playlist via our smartphone; or when pulling up the latest tools for collaborative work on our computer desktops in our office. This digital transformation is based on the use of advanced technologies (e.g., cloud services, mobile computing, sensors, and artificial intelligence). It is reflected in the way internal business processes, customer journeys as well as customer touchpoints, and business models are redesigned (Solis 2014; Krcmar 2015; Schuchmann and Seufert 2015; Meier et al. 2018).

In the course of this transformation, there has been much debate about the need for businesses and organizations to become more flexible, to become more innovative, and to become better at learning in order to deal with rapidly changing contextual conditions. These discussions involve professionals in the area of human resource development (HRD) and organization development (OD) who invoke concepts that were en vogue already some 30 years ago: "learning organization" and "culture of learning." Both concepts are relevant for HRD professionals designing and managing learning and development processes in organizations (Seufert 2013, 57-61 and 158-160), and discussions on the need for organizational learning and requisite cultures of learning take place during practitioner conferences (e.g.,

C. Meier $(\bowtie) \cdot$ S. Seufert · J. Guggemos · J. Spirgi

Institute for Business Education \& Educational Management, University of St.Gallen,

St. Gallen, Switzerland

e-mail: christoph.meier@unisg.ch

D. Ifenthaler et al. (eds.), Digital Transformation of Learning Organizations, 
Corporate Learning Conference, Munich ${ }^{1}$ ), in books published by reflective practitioners (e.g., Paine 2019) and in research in the area of organization development and learning organization (see Örtenblad (2019) and specifically Hoe (2019)).

In this chapter, we argue that research on the concept of the "learning organization" has, so far, failed to appreciate the relevance of two intertwined loci of learning in organizations and drivers for organizational performance: (1) advanced digital systems ("smart machines") and their ever-growing capacity for carrying out tasks and (2) collaboration of employees with smart machines and the specific skills and development strategies this requires. These two loci come together in hybrid activities that are performed collaboratively by humans and machines and that enable higher levels of performance and productivity (Fig. 5.1).

Fusion skills are skills required to achieve the full productive potential of collaboration between humans and smart machines. Examples are training smart machines for performance and acceptance; algorithmic testing, editing, and output interpretation; and managing the operations and performance of smart machines. Augmentation strategies are development strategies for humans to remain employable in the face of increasing numbers of smart machines in the workplace. The key strategies are step in, step up, step aside, step forward, and step narrow. We explain these strategies, and we provide results from empirical research among HRD professionals in German-speaking countries on their stance toward augmentation strategies. We conclude this chapter by stressing that HRD professionals (1) need to understand smart machines, fusion skills, and augmentation strategies as well as their implications at a personal level, (2) need to establish effective practices that are oriented to fusion skills and augmentation strategies, and in this way (3) need to contribute to the move toward a learning organization.

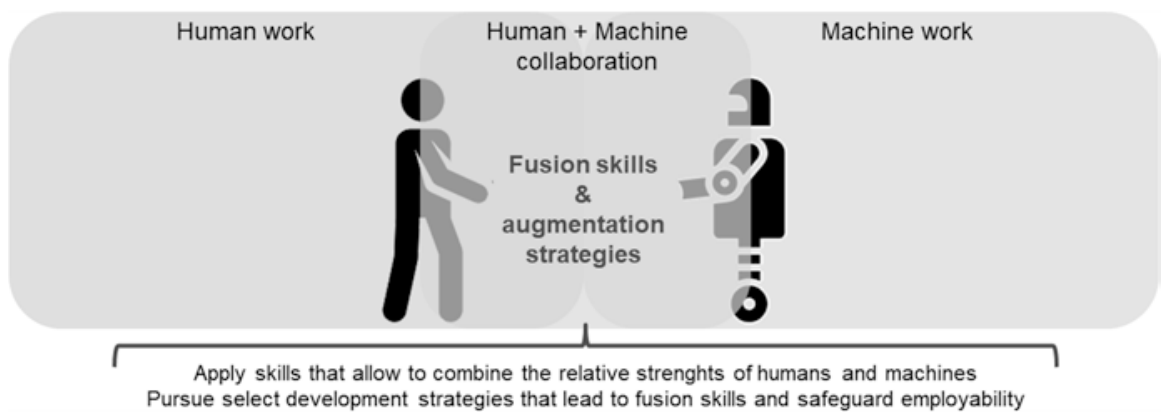

Fig. 5.1 Human + machine collaboration, fusion skills and augmentation strategies; icons by Flaticon

\footnotetext{
${ }^{1}$ See the list of contributions for the 2019 and 2020 editions of the conference at https://corporatelearning-konferenz.de/
} 


\subsection{Smart Machines and the Locus of Learning}

A specific quality of the digital transformation that we currently experience - what Wahlster (2017) refers to as the second wave of digitalization - is the involvement of artificial intelligence (AI) and AI-enabled smart machines. Increasingly, smart machines find their way into our homes (intelligent digital assistants like Alexa, Cortana, or Siri), into our cars (autonomous driving mode), and into our workplaces (collaborative robots, chatbots, AI-based apps and Web services, etc.). With these developments there is the question of how this affects learning in organizations and especially learning organizations.

There is quite a debate about how a "learning organization" can and should be conceptualized and where the learning actually takes place (Bui 2019). A definition we find useful and take as a starting point for this chapter is one that has been provided by Watkins and Marsick, originally in 1993:

"The learning organization is one that learns continuously and transforms itself. Learning takes place in individuals, teams, the organization and even the communities with which the organization interacts. Learning is a continuous, strategically used process - integrated with, and running parallel to, work. Learning results in changes in knowledge, beliefs and behaviors. Learning also enhances organizational capacity and growth." (Watkins and Marsick 2019, p. 53).

\subsubsection{The Role of Technology}

When reviewing research on the "learning organization" as it is represented in the comprehensive and current The Oxford Handbook of The Learning Organization (Örtenblad 2019), we notice that technology is almost completely absent. Out of the $30+$ contributions to this volume, only 2 mention technology as relevant to the learning organization. For Watkins and Marsick (2019, p. 55), technology is relevant to the learning organization in that organizations require systems to capture and share learning - for example, platforms for knowledge management or learning management. In the chapter contributed by Marquardt, technology figures more prominently as one of several subsystems of a learning organization: "The technology subsystem is composed of supporting, integrated technological networks and information tools that allow access to and exchange of information and learning. It includes technical processes, systems, and structures for collaborating, coaching, coordination, and other knowledge skills. (...) The two major components of the technology subsystem apply to managing knowledge and enhancing learning" (Marquardt 2019, p. 108).

Technology, as it emerges from these contributions, is relevant to the learning organization insofar as it provides "knowledge freeways" (Marquardt) and infrastructures to support exchange of information, collaboration, and access to learning resources. We disagree with this view as it misses two in our opinion key aspects: 1) 
artificial intelligence (AI) along with the availability of cheap processing power and huge data sets enables smart machines that can become continually more powerful - even without human intervention ${ }^{2}$ - and 2) the collaboration of humans and smart machines and the learning it takes to fully exploit the potential for performance and productivity gains of this collaboration.

\subsubsection{Learning at the Intersection of Smart Machines and Humans}

Recent development in the field of AI and particularly with regard to machine learning has resulted in "smart machines" that can perform activities that were previously unthought of. Smart machines have become extremely good not only at rule-based games such as chess, go, and poker or even formal debating. They are also employed in medical diagnosis, surveillance, engineering, journalism, precision farming, and many other areas. And, what is more, these smart machines can increasingly learn autonomously on the basis of mechanisms such as unsupervised learning or feedback learning (Jones 2017). This has led to an extensive debate about the future of work and employment, prominently starting with the so-called Oxford study (Frey and Osborne 2013).

What is missing in the research on the learning organization, from our point of view, is an appreciation of the relevance of (1) advanced digital systems ("smart machines") and (2) the interaction of employees with these smart machines (augmentation) as relevant loci of organizational learning.

Figure 5.2 illustrates the loci of organizational learning as proposed by Watkins and Marsick (2019) and their intersections. In particular, it highlights that (1) smart machines are an element of technology; that (2) the fusion skills required to fully capture their potential intersect with people (employees); and that (3) the augmentation strategies required to develop fusion skills intersect both with people and technologies.

As smart machines are increasingly becoming part and parcel of a wide range of work contexts (Brynjolfsson and McAfee 2014; Brynjolfson and McAfee 2017), the ability to productively employ such machines and to collaborate with them becomes an important aspect of organizational learning: learning that takes place at an individual level ("fusion skills"), at the level of technology (various forms of machine learning to improve on algorithms), and also at the level of the organization (e.g., establishing a culture of rigorous rethinking of business processes in order to capitalize on the potential of smart machines).

The focus in this chapter will be on the interaction of employees with smart machines as a locus of organizational learning. A source of inspiration for our thinking has been Kasparov's experience with chess computers. In his book Deep think-

\footnotetext{
${ }^{2} \mathrm{~A}$ striking example is this video (https://youtu.be/kopoLzvh5jY) provided by the company OpenAI that shows how software agents solve problems when playing hide and seek and how these agents become more powerful the longer they play against each other.
} 


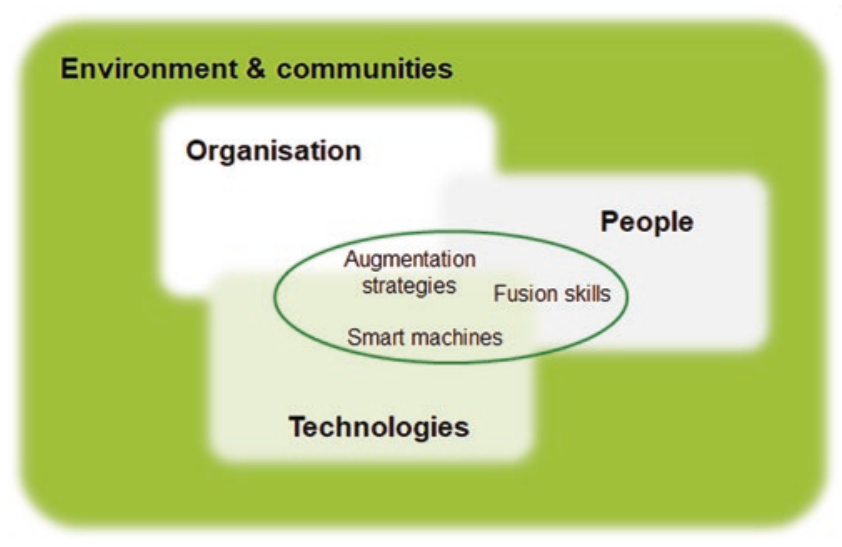

Fig. 5.2 Loci of learning and the focus of this chapter: smart machines at the intersection of organization, people, and technology

ing (Kasparov 2017a), Kasparov reflects on the implications of the powers of smart machines. In particular, he draws inspiration from developments such as freestyle chess, where teams of humans and machines (so-called centaurs) compete against each other. From the surprising finale to a chess tournament, he concludes the following:

"The winner was revealed to be not a Grandmaster with a state-of-the-art PC, but a pair of amateur American players (...) using three computers at the same time. Their skill at manipulating and "coaching" their computers (...) effectively counteracted the superior chess understanding of their Grandmaster opponents and the greater computational power of other participants. It was a triumph of process. (...) I represented my conclusion like this: weak human + machine + better process was superior to a strong computer alone and, more remarkably, superior to a strong human + machine + inferior process." (Kasparov 2017a, p. 246).

From this Kasparov concludes "Don't fear intelligent machines - work with them" (Kasparov 2017b).

In a similar vein, Brugger and Kimmich (Brugger and Kimmich 2017, p. 34) encourage the exploration of complementary cooperation between humans and smart machines in the industrial sector in order to attain new and previously impossible levels of productivity and value creation.

However, neither Kasparov nor Brugger and Kimmich explore in any detail just what is required for this complementary collaboration or what competences and strategies are required on the part of employees to make this happen. Two concepts have been proposed that we consider as highly relevant in this regard and which we have explored in our research and development work. One is the concept of "fusion skills" developed by Daugherty and Wilson (2018). The other is the concept of "augmentation strategies" developed by Davenport and Kirby (2016). We will present these concepts in the following sections. 


\subsection{Humans + Machines}

\subsubsection{Hybrid Activities}

Research and discourse about the impact of smart machines has, to a large extent, focused on the aspect of substitution: what tasks and activities smart machines currently are or soon will be able to perform and what the implications for the labor market are (e.g., Frey and Osborne 2013; Nedelkoska and Quintini 2018). Daugherty and Wilson (2018) argue that with this focus on either tasks performed by humans or alternatively tasks performed by machines, an important range of activities is lost out of sight: hybrid activities where humans and machines closely collaborate - as exemplified in the case of centaurs playing freestyle chess.

Two types of hybrid activities can be distinguished (Daugherty and Wilson 2018): (1) activities where humans complement smart machines and (2) activities where smart machines boost human capabilities. Examples of the first type are, among others, (i) training them for performance and acceptance (discovering, cleaning and tagging data, correcting errors, etc.), (ii) explaining them to various stakeholders and making sense of their output, and (iii) sustaining them by managing operations and performance. Examples of the second type are (iv) amplifying analytical powers by identifying trends in data, (v) enabling voice-powered access to information and services, and (vi) extending capabilities for seeing or hearing (Daugherty and Wilson 2018, pp. 116, 123, 127, 142, 145, 147) (Fig. 5.3).

Daugherty and Wilson (2018) argue that in order to carry out hybrid activities, specific skills on the part of humans are necessary. We will turn to these skills now.

\subsubsection{Fusion Skills as Success Factors for Learning and Performance}

There are several success factors for hybrid activities and for close collaboration of humans and smart machines that Daugherty and Wilson point out - based on survey research and consulting conducted by Accenture. In addition to mindset (readiness to radically rethink established business processes), openness to experimentation, leadership committed to the responsible use of smart machines and a data supply chain that fuels smart machines (2018, pp. 8; 13-15), they stress the importance of "fusion skills":

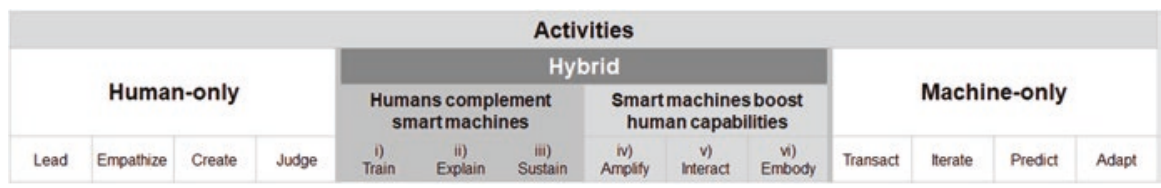

Fig. 5.3 Types of hybrid activities. (Source: Daugherty and Wilson 2018, p. 8 and passim) 
"In our work and research, we see evidence of at least eight novel fusion skills (...) that workers will need. Each skill draws on the fusion of human and machine talents within a business process to create better outcomes than working independently." (Daugherty and Wilson 2018, p. 184).

Daugherty and Wilson subsequently mention the following fusion skills (2018, pp. 186-203):

- Shaping the perception of smart machines in a responsible way.

- Passing judgments on the performance of smart machines and taking decisions for example, with regard to deviations from expected results or limits to the tasks allocated to machines.

- Intelligently interrogating smart machines in order to tease out meaningful analytic results from large data sets.

- Working "hand in hand" with smart machines.

- Reciprocal apprenticing, i.e., on the one hand, performing tasks alongside smart machines so that these can learn new skills (humans acting as role models, e.g., for a chatbot) and on the other hand learning to work well with these machines (e.g., by developing robust mental models of how they operate/perform).

As smart machines are becoming more commonplace in organizations and work environments, so are fusion skills becoming more relevant. Without the command of fusion skills in the workforce, organizations will not be able to fully take advantage of the continually developing potential of AI-based technologies. In consequence, they will miss out on one aspect of being learning organizations.

One area where smart machines and related fusion skills are becoming clearly visible is the area of care. Care robots and companion robots are piloted and deployed both in hospitals and in homes for the elderly (Bendel et al. 2020). This entails a range of new tasks for professional care givers as explained by Bendel et al. (ibid.) - tasks and skills that can be related to fusion skills as discussed above. Examples are the following:

- Introducing care robots to those who receive care and to establish realistic expectations as to what they are able to do and what they cannot (e.g., to what extent the robot is able to provide physical support in getting up or when leaning on it).

- Adjusting physical arrangements around a bed or seating area for convenient access of patients to the care robot and vice versa.

- Placing companion robots in areas where low noise levels allow interactions via natural language processing to run off sufficiently smooth.

- Deciding whether or not individual person recognition is sufficiently robust to allow care robots to carry drinks, meals, or even medicines to designated recipients.

- Ascertaining that defined taboos (e.g., refraining from touching the eyes or the necks of patients) and conventions such as closing doors to private rooms can and are reliably observed by care robots.

So far, we have argued that smart machines, and the fusion skills required to effectively collaborate with them, are important loci of learning in the digital age. 
Such fusion skills cannot be presupposed. Rather, they need to be diagnosed and - if lacking - developed. In case these fusion skills need to be developed, it is as yet unclear just how the workforce is to be developed in order to realize the potential that comes with smart machines. This is where the concept of "augmentation strategies" introduced by Davenport and Kirby (2016) becomes relevant.

\subsection{Augmentation Strategies}

Augmentation denotes - in contrast to substitution - the mutual enhancing and enablement of humans and smart machines, in particular in the context of collaboration of humans and smart machines. Augmentation can be differentiated into three categories (Raisamo et al. 2019, p. 132): augmented sensing (e.g., augmented vision, hearing, or smelling); augmented action (e.g., amplified force, movement, or telepresence); and augmented cognition (e.g., providing stored information during natural interaction). In the context of human resource development, Davenport and Kirby (2016) refer to augmentation strategies as developmental strategies related to smart machines in the workplace. Davenport and Kirby (2016) distinguish five such developmental strategies that are independent of industries and professions:

- Step in: Work with smart machines.

- Be knowledgeable about specific smart machines (and their limitations).

- Work productively with specific machines (and perhaps also train algorithms).

- Provide feedback to developers for further improvement.

- Step up: Evaluate and manage smart machines.

- Evaluate smart machines and results they achieve.

- Decide on where to employ which machine in what way (and where not to).

- Manage business processes involving smart machines.

- Step aside: Apply specific human capabilities (possibly building on the work of smart machines).

- Focus on tasks that go beyond information processing and that require specific human competences such as demonstrating empathy, motivating, or creative problem-solving.

- Step forward: Develop smart machines.

- Participate in the development of smart machines and their application to new domains.

- Step narrow: Specialize and evade smart machines.

- Focus on and specialize in a niche where the use of smart machines is not economical.

Table 5.1 provides examples of these strategies from different industries: 
Table 5.1 Augmentation strategies. (Based on Davenport and Kirby 2016)

\begin{tabular}{|c|c|c|c|}
\hline Strategy & $\begin{array}{l}\text { Example legal } \\
\text { profession }\end{array}$ & Example marketing & Example HRD \\
\hline Step in & $\begin{array}{l}\text { Develop deep expertise } \\
\text { in automated analysis of } \\
\text { contracts (eDiscovery) } \\
\text { on the basis of specific } \\
\text { software tools }\end{array}$ & $\begin{array}{l}\text { Develop deep expertise in } \\
\text { applying and monitoring } \\
\text { automated pricing } \\
\text { mechanisms }\end{array}$ & $\begin{array}{l}\text { Develop deep expertise in } \\
\text { learning analytics and } \\
\text { recommendation algorithms for } \\
\text { improved recommendation } \\
\text { system for digital learning } \\
\text { content }\end{array}$ \\
\hline Step up & $\begin{array}{l}\text { Take decisions on } \\
\text { where/how eDiscovery } \\
\text { tools will be relied on in } \\
\text { contract analysis and } \\
\text { trial preparation }\end{array}$ & $\begin{array}{l}\text { Orchestrate the use of } \\
\text { digital systems for brand } \\
\text { management }\end{array}$ & $\begin{array}{l}\text { Orchestrate decisions on the } \\
\text { ethical use of personalized user } \\
\text { data in order to improve } \\
\text { intelligent learning systems }\end{array}$ \\
\hline $\begin{array}{l}\text { Step } \\
\text { aside }\end{array}$ & $\begin{array}{l}\text { Focus on, e.g., } \\
\text { consulting and customer } \\
\text { management (while } \\
\text { building on results } \\
\text { provided by smart } \\
\text { machines) }\end{array}$ & $\begin{array}{l}\text { Focus on creative work } \\
\text { and customer } \\
\text { management (while } \\
\text { building on results } \\
\text { provided by smart } \\
\text { machines) }\end{array}$ & $\begin{array}{l}\text { Provide coaching for workplace } \\
\text { learning supported by } \\
\text { appropriate digital tools and } \\
\text { personalized, intelligent } \\
\text { (learning) systems }\end{array}$ \\
\hline $\begin{array}{l}\text { Step } \\
\text { forward }\end{array}$ & $\begin{array}{l}\text { Participate in the } \\
\text { (further) development of } \\
\text { solutions for eDiscovery }\end{array}$ & $\begin{array}{l}\text { Participate in the (further) } \\
\text { development of solutions } \\
\text { for optimizing the } \\
\text { placement of } \\
\text { advertisements }\end{array}$ & $\begin{array}{l}\text { Contribute technical expertise } \\
\text { to the development of a new } \\
\text { intelligent tools, e.g., chatbots } \\
\text { helping to sketch a personal } \\
\text { development plan }\end{array}$ \\
\hline $\begin{array}{l}\text { Step } \\
\text { narrow }\end{array}$ & $\begin{array}{l}\text { Focus on legal } \\
\text { counseling for underage } \\
\text { minors }\end{array}$ & $\begin{array}{l}\text { Focus on marketing } \\
\text { activities in public spaces }\end{array}$ & $\begin{array}{l}\text { Facilitate design thinking } \\
\text { sessions on solutions for a } \\
\text { culture of learning and } \\
\text { innovation }\end{array}$ \\
\hline
\end{tabular}

Davenport and Kirby focus on highly qualified knowledge workers, for example, in the legal profession, in financial services, or in marketing. In the course of joint development work with HRD professionals from major corporations in the context of our innovation circle on augmentation (Meier 2019), it became apparent that these developmental strategies are also relevant for other sections of the workforce. Examples are skilled workers in manufacturing, in logistics, and in the area of customer services such as work in mail sorting centers or call centers.

There are, however, differences. Davenport and Kirby (2016) imply that augmentation strategies are a matter of individual preference and personal perseverance. This may be the case in the context of small professional service organizations and in the case of highly skilled professionals. In the context of large businesses and corporations, however, augmentation strategies are also a matter of strategic initiatives in the area of workforce management. In these contexts, (line) management often decides on which augmentation strategy is to be pursued by which job family (Meier et al. 2019, p. 830).

The important point for our argument here is that augmentation strategies are relevant to large parts of the workforce and therefore are a relevant concern for HRD professionals. Preparing employees from entire job families for very different 
production and service processes, for collaboration with smart machines, and for continually changing competency requirements is a major challenge for any organization and, in particular, for HRD professionals. To face this challenge, HRD professionals need to go beyond the typical activities of needs analysis and competency development. Rather, four interrelated groups of tasks are required (Meier 2019):

- Needs analysis and competency development activities

When smart machines are introduced to the workplace, work processes are redesigned, and the allocation of tasks and activities between humans and machines changes. For specific job families and jobs, augmentation strategies need to be defined, and, from these, specific development needs can be derived. For example, what skills and competences are required for a "step in" strategy in contrast to a "step aside" or a "step up" strategy?

- Facilitation of change

As smart machines are becoming more widespread in workplaces, more and more job profiles change. These changes may be more or less extensive and may require significant changes in the way people view their work and profession. Providing coaching and support in this transition process is important.

- Measurements, stage gates, and evaluation

In supporting competency development and in facilitating change, HRD professionals need to take measures on aspect such as awareness of smart machines and the changes they are about to induce, readiness for change and for the progression to an adjusted task and job profile, status on new skills and competences, and, last but not least, performance in new tasks.

- Tools and work aids

In the context of the abovementioned innovation circle, specific work aids related to these three groups of tasks have been drafted, tested, and refined. These tools and work aids need to be understood and possibly adapted to specific contextual conditions.

Figure 5.4 illustrates these four intersecting groups of tasks as they were concretized in the course of the innovation circle (Meier 2019).

Developing the workforce in accordance with the requirements of specific augmentation strategies and facilitating the transition to altered task and job profiles are demanding tasks for HRD professionals. We are convinced that the more effective HRD professionals are in implementing these four interrelated work streams, the better their organizations will be able to move forward with smart machines, augmentation, and altered business processes - i.e., the better they are on their way toward being learning organizations in the age of smart machines. For this, it is important that HRD professionals understand the concept of fusion skills and also the different augmentation strategies as well as their implications. We will elaborate on this in the next section. 


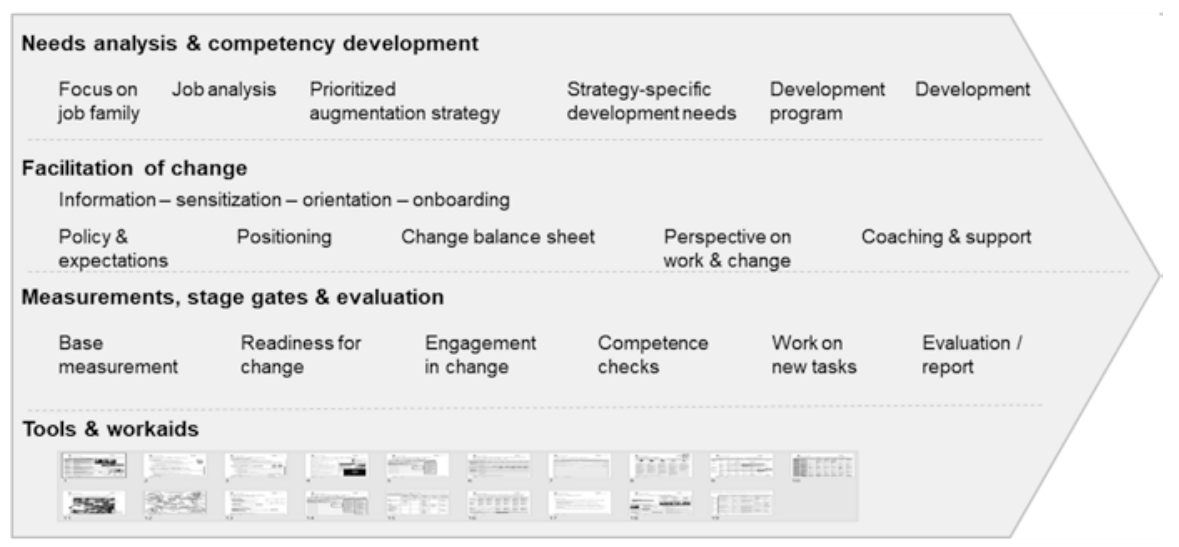

Fig. 5.4 Four intersecting work streams in applying augmentation strategies for workforce development. (Adapted from Meier et al. 2019, p. 835)

\subsection{The Contribution of Human Resource Development}

In the previous sections, the following argument was developed: With smart machines spreading in the workplace, an important aspect of moving toward a learning organization is a HRD process oriented both to the potential of and to the requirements for productively working with smart machines. We argue that HRD needs to be aware of the importance of fusion skills as well as augmentation strategies and needs to be able to systematically develop these.

What does all this mean for HRD and HRD professionals? In order to clarify this, we build on the conceptual distinction of three levels of HRD-specific competences developed by Martin and Grudziecki (2006, p. 255):

- Level 1: competences related to digital transformation and smart machines at the level of individual contributors in HRD.

- Level 2: capabilities related to digital transformation and smart machines at the level of the HRD function.

- Level 3: capabilities related to supporting digital transformation and learning at the organizational level.

Proceeding from the representation provided in Fig. 5.5, the question is: Do HRD professionals have the competences (level 1), and are they collectively capable of driving the HRD function (level 2) in order to facilitate transformation and learning at the organizational level (level 3)?

For 3 years now, we have been conducting survey research that sheds light on this question (Seufert et al. 2019a; Seufert et al. 2020, p. 61). This research, which has been carried out in Germany, Switzerland, and Austria, specifically investigates 


\begin{tabular}{|c|c|c|c|c|}
\hline \multirow[t]{2}{*}{ Level III: } & \multicolumn{4}{|c|}{$\begin{array}{l}\text { Capabilities related to digital transformation and learning } \\
\text { at the level of the entire organisation }\end{array}$} \\
\hline & & & & $\downarrow$ \\
\hline LevelII: & \multicolumn{4}{|c|}{$\begin{array}{l}\text { Capabilities related to digital transformation and smart machines } \\
\text { at the level of the HRD function }\end{array}$} \\
\hline & & & & 4 \\
\hline & & & $\forall$ & $i$ \\
\hline Levell: & \multicolumn{4}{|c|}{$\begin{array}{l}\text { Competences related to digital transformation and smart machines } \\
\text { at the level of individual contributors in HRD }\end{array}$} \\
\hline $\begin{array}{l}\text { Compe } \\
\text { Require }\end{array}$ & $\begin{array}{l}\text { tence } \\
\text { ement }\end{array}$ & $\begin{array}{l}\text { Professional } \\
\text { Knowledge }\end{array}$ & $\begin{array}{l}\text { Instrumental } \\
\text { Skills }\end{array}$ & Attitudes \\
\hline \multicolumn{2}{|c|}{$\begin{array}{l}\text { Shaping digital } \\
\text { transformation } \\
\text { of HRD }\end{array}$} & $\begin{array}{l}\text { HRD relevant knowledge } \\
\text { - Knowledge about advanced } \\
\text { digitalisation } \\
\text { (e.g. big data and Al) } \\
\text { - Knowledge about the smart } \\
\text { application } \\
\text { (e.g. ITS, learning analytics) }\end{array}$ & $\begin{array}{l}\text { "Soft" skills } \\
\text {-Dealing with digital } \\
\text { information } \\
\text {-Create, share digital } \\
\text { content } \\
\text {-Collaboration with } \\
\text { digital tools } \\
\text {-Netiquette }\end{array}$ & $\begin{array}{l}\text { Positive attitudes } \\
\text {-Interest in dealing } \\
\text { with digitization } \\
\text {-Advantages of } \\
\text { advanced } \\
\text { digitization than } \\
\text { outweigh } \\
\text { disadvantages }\end{array}$ \\
\hline \multicolumn{2}{|c|}{$\begin{array}{c}\text { Shaping digital } \\
\text { transformation } \\
\text { of the } \\
\text { organisation } \\
\text { as a whole }\end{array}$} & $\begin{array}{l}\text { Organisational knowledge } \\
\text { - Developing digital } \\
\text { competence at scale } \\
\text { - Agile leadership systems } \\
\text { - Change Management }\end{array}$ & $\begin{array}{l}\text { «Hard» skills } \\
\text {-Solving technical } \\
\text { problems } \\
\text {-Protecting digital } \\
\text { devices } \\
\text {-Programming }\end{array}$ & $\begin{array}{l}\text { Negative attitudes } \\
\text {-Fear of becoming } \\
\text { superfluous } \\
\text {-Fear of excessive } \\
\text { demands }\end{array}$ \\
\hline
\end{tabular}

Fig. 5.5 Three levels of transformation. (Adapted from Seufert et al. 2019)

the state of digital transformation in the people development function, the status of learning professionals with regard to knowledge on advanced digitalization, their attitude toward digital transformation, and the augmentation strategies they see for themselves. In these studies, HRD professionals from industries such as manufacturing, financial services, public administration, logistics, IT, and telecommunications participated (225 in 2018, 160 in 2019). HRD professionals from manufacturing, financial services, public administration, logistics, IT, and telecommunications as well as several other industries participated.

With regard to the question as to whether or not HRD professionals have the competences and capabilities to drive and support digital transformation at the three levels pointed out above, two results of this research are particularly relevant. One relates to the knowledge of learning professionals on aspects of advanced digitalization in the domain of talent development. As can be seen in Fig. 5.6, HRD professionals mostly regard their knowledge about these aspects as not yet fully developed.

This result may indicate that HRD professionals are not yet able to implement development programs focused on augmentation strategies - not the least because they may not fully understand the dimension of change. However, other results from this research reveal that HRD professionals indeed see themselves as up to the task of moving their organizations forward. One is that a large majority of HRD profes- 
( $n=160$, figures in \%)

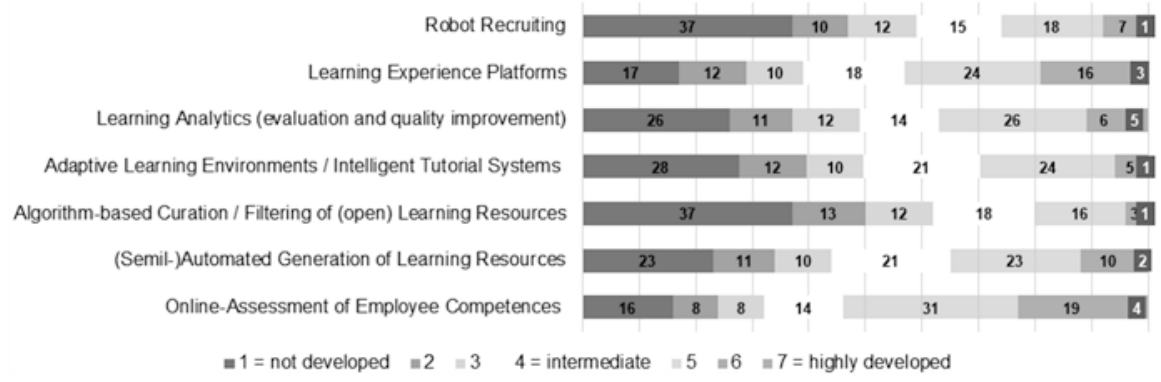

Fig. 5.6 Self-assessment on knowledge relating to aspects of advanced digitalization in talent development. (Source: Seufert et al. 2019b, p. 14)

( $n=160$, figures in \%)

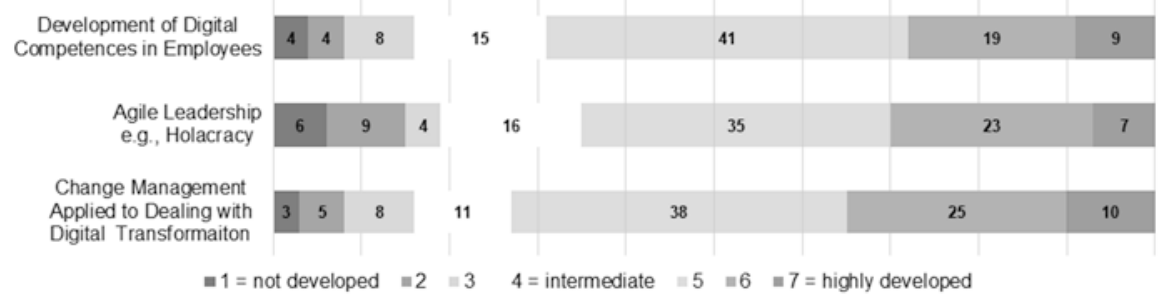

Fig. 5.7 Self-assessment prompted by the following stimulus: "How do you rate your knowledge regarding the following methods and procedures?" (Source: Seufert et al. 2019b, p. 15)

sionals have positive attitudes toward digital transformation and do not feel threatened by it. The other is that they mostly see themselves as capable of supporting the development of digital capabilities and digital change (see Fig. 5.7, top and bottom item).

While talent development professionals may not yet fully appreciate the dimension of change resulting from smart machines coming to the workplace, they are nevertheless open to this change and also see themselves as capable of (1) developing digital competences in employees and (2) supporting change related to digital transformation.

As part of this survey research, we have been asking HRD professionals directly about how they position themselves with regard to augmentation strategies. After all, AI-driven solutions such as intelligent tutoring systems or chatbot-based learning environments are gaining momentum in the field of human resource development. In order to enable a well-founded positioning, a short explanatory text and a table with a characterization of the five augmentation strategies were provided. Two items each operationalize the five augmentation strategies. Examples of these question items are the following (items are translated from German):

- "I see my responsibility in HRM in the productive use of AI-based solutions in the process of people development work" ("step in"). 
- "I see my responsibility in HRM in the evaluation of currently available augmentation solutions for HRD work" ("step up").

- "I see my responsibility in HRM in offering development consulting for employees" ("step aside").

With regard to augmentation strategies, HRD professionals currently favor a "step aside" strategy for themselves. On average, more than $80 \%$ of talent development professionals participating in the survey see their activities in line with this strategy. The "step up" strategy is ranked in second place, followed by "step in" and "step forward"; see Fig. 5.8.

In this vein, a critical point could be the validity of the HRD professionals' selfassessment with regard to - on the one hand - supporting digital transformation and - on the other hand - their readiness for pursuing relevant augmentation strategies. For example, "step up" emerges as an augmentation strategy that HRD professionals regard as highly relevant to their work (ranked in second place). Yet, we see this strategy as one that is feasible for only a few persons as we expect the demand for work and expertise regarding the evaluation of smart machines and their management as rather limited within organizations - at least compared to the demand for roles that practice "step in" or "step aside." In order to resolve this, more research is required. The challenge is that the concepts of fusion skills and augmentation strategies are new and rather abstract. Therefore, it may be a challenge to ensure a valid self-assessment.
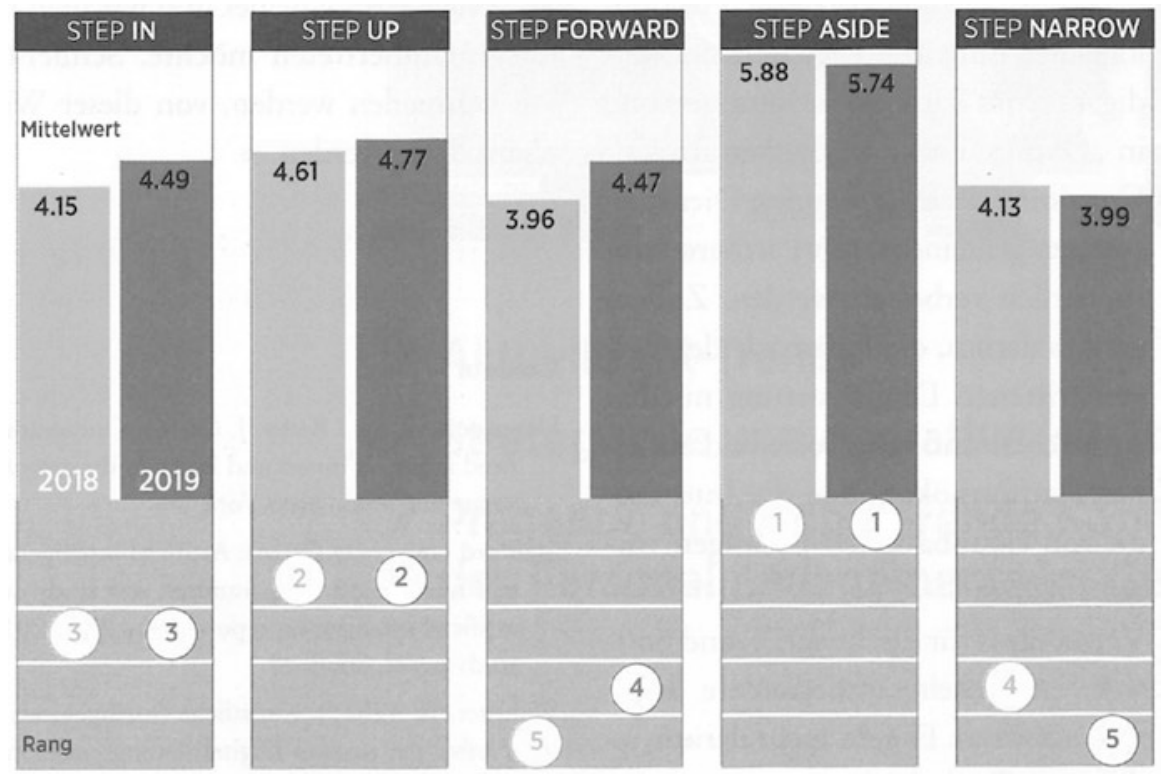

Fig. 5.8 Preference ranking of augmentation strategies for talent development professionals. (Source: Seufert et al. 2020, p. 61) 


\subsection{The Learning Organization in the age of Smart Machines}

The point of departure for this chapter was the following understanding of a learning organization: "The learning organization is one that learns continuously and transforms itself. Learning takes place in individuals, teams, the organization and even the communities with which the organization interacts. Learning is a continuous, strategically used process - integrated with, and running parallel to, work" (Watkins and Marsick 2019, p. 53). Against this backdrop, we have developed the following sequence of arguments in this chapter.

In the literature on the learning organization, the role of technology has mostly been limited to it providing "knowledge freeways" and infrastructures to support exchange of information, collaboration, and access to learning resources. What is missing is an appreciation of the relevance of two intertwined loci of learning in organizations: (1) advanced digital systems ("smart machines") and their evergrowing capacity for carrying out tasks and (2) the interaction of employees with these smart machines.

Smart machines are able to perform narrowly defined tasks by themselves, and they are continually becoming more powerful. The real potential lies, however, in the productive collaboration of humans and smart machines. This collaboration takes the form of hybrid activities where humans complement smart machines and smart machines boost human capabilities. Hybrid activities are an important driver for organizational performance.

A prerequisite for hybrid activities and the performance they make possible are what Daugherty and Wilson call "fusion skills" (Daugherty and Wilson 2018). These comprise skills such as shaping the perception of smart machines in a responsible way, passing judgments on the performance of smart machines and taking appropriate decisions, intelligently interrogating smart machines in order to tease out meaningful analytic results, working "hand in hand" with smart machines, and reciprocal apprenticing.

The availability of such fusion skills cannot be taken for granted. Rather, fusion skills need to be diagnosed and - if lacking - developed. A relevant framework for developing these and other skills related to smart machines is "augmentation strategies" as coined by Davenport and Kirby: "step in"; "step up"; "step aside”; "step forward"; and "step narrow" (Davenport and Kirby 2016).

Preparing entire job families (1) for the very different production and service processes that are possible with smart machines, (2) for productive collaboration with smart machines, and (3) for continually changing competency requirements (after all, these machines are continually becoming more powerful) is a major challenge for any organization. It is a challenge that marks a moment of truth with regard to coping with dynamic change and also with regard to being a learning organization.

This challenge is multi-faceted. It requires an understanding of key concepts such as fusion skills and augmentation strategies. It also requires performance in 
several interrelated groups of tasks: needs analysis and competency development; facilitation of change; measurement and evaluation; and, finally, appropriate use and adaptation of tools and work aids. This challenge is located in the realm of HRD professionals.

As current research indicates (Seufert et al. 2020), HRD professionals in Germanspeaking countries rate their own knowledge on aspects of advanced digitalization in the domain of talent development mostly as not fully developed. Hence, the question emerges whether they already are positioned as effective supporters of a move toward a learning organization in a context where smart machines are becoming increasingly prevalent. However, research results also indicate that HRD professionals see themselves as up to the task, in particular because they see themselves as capable of supporting the development of digital capabilities, more agile organization, and digital change.

In order to foster the move toward a learning organization in a digital age characterized by increasingly powerful smart machines, HRD professionals may need to follow three steps: Firstly, they need to better understand smart machines, fusion skills, and augmentation strategies as well as their implications - at a personal level as well as at a team and an organizational level. Secondly, they need to establish effective practices at the level of the HRD function so that HRD professionals themselves can make effective use of and respectively can effectively collaborate with smart machines in their immediate work context - for example, intelligent tutoring systems or learning environments supported by chatbots. Thirdly, they need to make available these capabilities to the entire organization in order to support - where required - the move toward a learning organization in a digital age.

Besides these challenges for HRD professionals, there are, however, also challenges for research and development in this area. In particular, more research on fusion skills and augmentation strategies is required. How to operationalize and to validly and reliably diagnose fusion skills? How to operationalize and diagnose augmentation strategies? How to develop and evaluate tools and processes that support both the development of fusion skills and augmentation strategies? These are interesting times and it is unlikely that HRD runs out of challenging tasks.

\section{References}

Bendel, O., Gasser, A., \& Siebenmann, J. (2020, March). Co-robots as care robots. Vortrag bei "Applied AI in healthcare: Safety, community, and the environment". AAAI 2020 Spring Symposium Series, Stanford University, Palo Alto.

Brugger, S., \& Kimmich, M. (2017). Onboarding des Kollegen Roboter. Changement, 2017(03), $31-34$.

Brynjolfson, E., \& McAfee, A. (2017, November). Von Managern und Maschinen. Harvard Business Manager 23-34.

Brynjolfsson, E., \& McAfee, A. (2014). The second machine age: Work, progress, and prosperity in a time of brilliant technologies. New York: Norton. 
Bui, H. T. M. (2019). On definitions of the learning organization: Toward a new definition of learning organization. In A. Örtenblad (Ed.), Oxford handbooks. The Oxford handbook of the learning organization (pp. 137-147). Oxford: Oxford University Press.

Daugherty, P. R., \& Wilson, H. J. (2018). Human + machine: Reimagining work in the age of AI. Boston: Harvard Business Review Press.

Davenport, T. H., \& Kirby, J. (2016). Only humans need apply: Winners and losers in the age of smart machines (1st ed.). New York: Harper Business.

Frey, C. B., \& Osborne, M. (2013). The future of employment. Oxford. Retrieved from University of Oxford website: https://www.oxfordmartin.ox.ac.uk/downloads/academic/The_Future_of_ Employment.pdf

Hoe, S. L. (2019). The topicality of the learning organization: Is the concept still relevant today? In A. Örtenblad (Ed.), Oxford handbooks. The Oxford handbook of the learning organization (pp. 19-32). Oxford: Oxford University Press.

Jones, M. T. (2017). A beginner's guide to artificial intelligence, machine learning, and cognitive computing: Explore some of the important aspects of AI and its subfields. Retrieved from https://developer.ibm.com/articles/cc-beginner-guide-machine-learning-ai-cognitive/.

Kasparov, G. (2017a). Deep thinking: Where machine intelligence ends and human creativity begins. London: John Murray (Publishers.

Kasparov, G. (2017b, April). Don't fear intelligent machines: Work with them. TED 2017. Retrieved from https://www.ted.com/talks/ garry_kasparov_don_t_fear_intelligent_machines_work_with_them.

Krcmar, H. (2015). Leadership in digital transformation. Retrieved from https://open.sap.com/ courses/ldt1-tl

Marquardt, M. J. (2019). Building learning organizations with action learning. In A. Örtenblad (Ed.), Oxford handbooks. The Oxford handbook of the learning organization (pp. 105-118). Oxford: Oxford University Press.

Martin, A., \& Grudziecki, J. (2006). DigEuLit: Concepts and tools for digital literacy development. Innovations in Teaching \& Learning in Information \& Computer Sciences, 5(4), 249267. https://doi.org/10.11120/ital.2006.05040249.

Meier, C. (2019). Augmentationsstrategien als Orientierungsrahmen für die Personalentwicklung: Abschlussbericht zum scil Innovationskreis 2018/2019. St. Gallen. Retrieved from Universität St. Gallen / scil website: https://www.scil.ch/produkt/ scil-arbeitsbericht-30-augmentationsstrategien-personalentwicklung/

Meier, C., Bäcker, D., \& Seibold, D. (2018). Digitale transformation und L\&D: Ergebnisse einer Standortbestimmung und Handlungserfordernisse. scil Arbeitsbericht 29. St. Gallen.

Meier, C., Seufert, S., \& Guggemos, J. (2019). Arbeitswelt 4.0 und Smart Machines: Augmentation als Herausforderung für die Personalentwicklung. HMD Praxis der Wirtschaftsinformatik, 56(4), 823-839.

Nedelkoska, L., \& Quintini, G. (2018). Automation, skills use and training. OECD Social, Employment and Migration Working Papers No. 202. Paris.

Örtenblad, A. (Ed.). (2019). Oxford handbooks. The Oxford handbook of the learning organization. Oxford: Oxford University Press.

Paine, N. (2019). Workplace learning: How to build a culture of continuous employee development. London: Kogan Page Limited.

Raisamo, R., Rakkolainen, I., Majaranta, P., Salminen, K., Rantala, J., \& Farooq, A. (2019). Human augmentation: Past, present and future. International Journal of Human-Computer Studies, 131, 131-143. https://doi.org/10.1016/j.ijhcs.2019.05.008.

Schuchmann, D., \& Seufert, S. (2015). Corporate learning in times of digital transformation: A conceptual framework and service portfolio for the learning function in banking Organisations. International Journal of Advanced Corporate Learning (IJAC), 8(1), 31-39.

Seufert, S. (2013). Bildungsmanagement: Einführung für Studium und Praxis. Stuttgart: Schäffer-Poeschel. 
Seufert, S., Guggemos, J., \& Meier, C. (2019, June). Shaping digital transformation: How can HRD competences be conceptualised with a FOCUS on augmentation? Paper presented at Conference of the European Academy of Management (EURAM), Lissabon.

Seufert, S., Guggemos, J., Meier, C., \& Helfritz, K. H. (2019a). Augmentation: Personalentwicklung in der digitalen Transformation.: Ergebnisse einer empirischen Studie. Personalführung, 2019/02, 58-63.

Seufert, S., Guggemos, J., Meier, C., \& Helfritz, K. H. (2019b). Digitale Kompetenzen von Personalentwicklern: Digitale Reife und Augmentationsstrategien in der Personalentwicklung. St.Gallen.

Seufert, S., Guggemos, J., Meier, C., \& Helfritz, K. H. (2020). Von der Digitalisierung zur Künstlichen Intelligenz: Augmentation als Leitmotiv. Personalführung, 2020/04, 56-62.

Solis, B. (2014). The 2014 state of digital transformation. Retrieved from https://www.prophet. com/thinking/2014/07/the-2014-state-of-digital-transformation/

Wahlster, W. (2017). Künstliche Intelligenz als Treiber der zweiten Digitalisierungswelle. IM+io Das Magazin Für Innovation, Organisation Und Management, 2017(2 / Juni), 10-13. Retrieved from https://www.aws-institut.de/im-io/product/super-smart-society/

Watkins, K. E., \& Marsick, V. J. (2019). Conceptualizing an organization that learns. In A. Örtenblad (Ed.), Oxford handbooks. The Oxford handbook of the learning organization (pp. 51-66). Oxford: Oxford University Press.

Open Access This chapter is licensed under the terms of the Creative Commons Attribution 4.0 International License (http://creativecommons.org/licenses/by/4.0/), which permits use, sharing, adaptation, distribution and reproduction in any medium or format, as long as you give appropriate credit to the original author(s) and the source, provide a link to the Creative Commons license and indicate if changes were made.

The images or other third party material in this chapter are included in the chapter's Creative Commons license, unless indicated otherwise in a credit line to the material. If material is not included in the chapter's Creative Commons license and your intended use is not permitted by statutory regulation or exceeds the permitted use, you will need to obtain permission directly from the copyright holder.

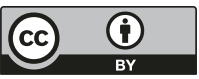

